NASA/TM-2006-214038

\title{
Application of Composite Mechanics to Composites Enhanced Concrete Structures
}

Christos C. Chamis

Glenn Research Center, Cleveland, Ohio

Pascal K. Gotsis

Technical Education Institute, Serres, Greece 
Since its founding, NASA has been dedicated to the advancement of aeronautics and space science. The NASA Scientific and Technical Information (STI) Program Office plays a key part in helping NASA maintain this important role.

The NASA STI Program Office is operated by Langley Research Center, the Lead Center for NASA's scientific and technical information. The NASA STI Program Office provides access to the NASA STI Database, the largest collection of aeronautical and space science STI in the world. The Program Office is also NASA's institutional mechanism for disseminating the results of its research and development activities. These results are published by NASA in the NASA STI Report Series, which includes the following report types:

- $\quad$ TECHNICAL PUBLICATION. Reports of completed research or a major significant phase of research that present the results of NASA programs and include extensive data or theoretical analysis. Includes compilations of significant scientific and technical data and information deemed to be of continuing reference value. NASA's counterpart of peerreviewed formal professional papers but has less stringent limitations on manuscript length and extent of graphic presentations.

- TECHNICAL MEMORANDUM. Scientific and technical findings that are preliminary or of specialized interest, e.g., quick release reports, working papers, and bibliographies that contain minimal annotation. Does not contain extensive analysis.

- CONTRACTOR REPORT. Scientific and technical findings by NASA-sponsored contractors and grantees.
- CONFERENCE PUBLICATION. Collected papers from scientific and technical conferences, symposia, seminars, or other meetings sponsored or cosponsored by NASA.

- SPECIAL PUBLICATION. Scientific, technical, or historical information from NASA programs, projects, and missions, often concerned with subjects having substantial public interest.

- TECHNICAL TRANSLATION. Englishlanguage translations of foreign scientific and technical material pertinent to NASA's mission.

Specialized services that complement the STI Program Office's diverse offerings include creating custom thesauri, building customized databases, organizing and publishing research results ... even providing videos.

For more information about the NASA STI Program Office, see the following:

- Access the NASA STI Program Home Page at http://www.sti.nasa.gov

- E-mail your question via the Internet to help@sti.nasa.gov

- Fax your question to the NASA Access Help Desk at 301-621-0134

- Telephone the NASA Access Help Desk at 301-621-0390

- Write to:

NASA Access Help Desk

NASA Center for AeroSpace Information 7121 Standard Drive

Hanover, MD 21076 
NASA/TM-2006-214038

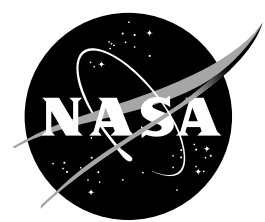

\section{Application of Composite Mechanics to Composites Enhanced Concrete Structures}

Christos C. Chamis

Glenn Research Center, Cleveland, Ohio

Pascal K. Gotsis

Technical Education Institute, Serres, Greece

Prepared for the

16th European Conference of Fracture cosponsored by ESIS, ASTM, SMS, AIAS, JSEM, BSSM, SEM, and EURASEM Alexandroupolis, Greece, July 3-7, 2006

National Aeronautics and

Space Administration

Glenn Research Center 
This report is a formal draft or working paper, intended to solicit comments and ideas from a technical peer group.

This report contains preliminary findings, subject to revision as analysis proceeds.

This report is a preprint of a paper intended for presentation at a conference. Because of changes that may be made before formal publication, this preprint is made available with the understanding that it will not be cited or reproduced without the permission of the author.

This work was sponsored by the Fundamental Aeronautics Program at the NASA Glenn Research Center.

Available from

NASA Center for Aerospace Information 7121 Standard Drive

Hanover, MD 21076
National Technical Information Service 5285 Port Royal Road Springfield, VA 22100 


\title{
Application of Composite Mechanics to Composites Enhanced Concrete Structures
}

\author{
Christos C. Chamis \\ National Aeronautics and Space Administration \\ Glenn Research Center \\ Cleveland, Ohio 44135 \\ Pascal K. Gotsis \\ Technical Education Institute \\ Terma Magnisias Str \\ TK62124, Serres, Greece
}

\begin{abstract}
A new and effective method is described to design composites to repair damage or enhance the overload strength of concrete infrastructures. The method is based on composite mechanics which is available in computer codes. It is used to simulate structural sections made from reinforced concrete which are typical in infrastructure as well as select reinforced concrete structures. The structural sections are represented by a number of layers through the thickness where different layers are used in concrete, and for the composite. The reinforced concrete structures are represented with finite elements where the element stiffness parameters are from the structural sections which are represented by composite mechanics. The load carrying capability of the structure is determined by progressive structural fractural. Results show up to 40 percent improvements for damage and for overload enhancement with relatively small laminate thickness for the structural sections and up to three times for the composite enhanced select structures (arches and domes).
\end{abstract}

\section{Introduction}

Reinforced concrete is widely used in the construction industry. Concrete tends to crack, chip and be damaged as a result of inadvertent loads or overloads which may not have been accounted for in the initial design. The damage in concrete structures may extend to a state where the safety of that structure becomes a major concern. Recently, a considerable effort is being expended on repairing damaged or upgrading concrete structures by using fiber reinforced composites. For example, several sessions were devoted to this subject at a recent International SAMPE Symposium and Exhibition, Long Beach, California (ref. 1). The use of composites is natural since the repairing composites tend to be thin laminates which are easily bonded to damaged concrete structures made from cylindrical and flat surfaces in general. Different methods for designing and analyzing thin laminates have been developed and are available in many computer codes. Recent research demonstrates that damaged concrete structures and their repairing composites can be simulated simultaneously by composite mechanics which is available in some of those computer codes (refs. 2 to 3 ). By using composite mechanics, we can represent any concrete structural section by assuming that it consists of several layers through its thickness. In so doing, we take advantage of all the features available in computer codes for composite mechanics - for example, ICAN (Integrated Composite Analyzer) (ref. 4). The objective of the proposed paper is to describe those features and attendant computer codes, and illustrate their application to select reinforced concrete structural sections and structures. The composite mechanics is described briefly. Then, it is applied to select structural sections and to select structures (special arch and a dome). Note that results presented herein are computational. Comparisons with other methods and concrete code requirements are included in the references cited. 


\section{Composite Mechanics}

Composite behavior is simulated by assuming that the composite consists of several layers (plies) through its thickness. The plies include both fiber and matrix. Theoretically, we can represent any concrete structural section by assuming that it consists only of several layers through its thickness where: (1) most layers consist only of concrete (matrix); (2) one or two layers consists of concrete and steel Rbars (matrix and fibers); (3) one or several layers of the composite repair laminate. Composite mechanics is natural, then, since we can represent concrete structural sections as layers and also composite laminates as layers. By so doing, we take advantage of all the features available in computer codes for composite mechanics-for example, ICAN (ref. 4).

\section{Brief Description of ICAN Features}

A brief description of ICAN features is instructive because it demonstrates its versatility and ideal application to reinforced concrete. ICAN evolved from research conducted in composite micromechanics and macromechanics over the last four decades at NASA Glenn Research Center. The primary goal of that research is to develop composite mechanics theories and structural analysis methods that range in scale from micromechanics to structural analysis in one integrated code, figure 1, (ref. 4). The micromechanics theories are represented by simplified equations that have been corroborated by detailed three-dimensional finite element analyses (ref. 5). ICAN is designed to carry out a comprehensive analysis including the hygral, thermal and mechanical properties/responses of multilayered continuous fiber reinforced polymer matrix composites. The analysis contains the essential features required to obtain the material properties integrated through the thickness to effectively design structural components made from fiber composites. It can analyze standard composites, i.e., composites consisting of one type of fiber in a matrix forming a ply lamina or a layer. In addition to that, the code can also analyze an interplay or intraply hybrid composite system. This is a useful feature because different types of R-bars can be included in the same section. These layers are then arranged with prescribed orientations to form a composite laminate. The micromechanics equations in ICAN take into account the effects of temperature and/or moisture gradients through the thickness. This feature can be very useful in modeling curing of concrete or degradation in moist-type environments. However, within each layer, the temperature or moisture is assumed to be constant. ICAN includes a dedicated databank of constituent material properties of commonly available fibers and matrices, and also allows the user to build in a very userfriendly manner, a database of new material properties when they become available. The user needs to specify only a code name of constituent and the code gets all the appropriate material properties from the databank.

Input to ICAN includes composite geometry, i.e., the ply or the layer lay-up and fiber volume ratios, thicknesses and the orientations of the layers, code names for the constituent materials, factors reflecting the fabrication process and the loading conditions. ICAN performs a micromechanics and macromechanics analysis of the laminate, ICAN output includes the various ply and composite properties, composite structural response, and composite stress analysis results with details of failure. Additional features unique to ICAN include ply stress-strain relations, stress concentrations around a circular hole, free-edge stresses, material properties input for finite element analysis using MSC/NASTRAN and other general purpose finite element codes, failure loads based on maximum stress criterion and laminate failure stresses based on first-ply failures, etc. The output from the program can be tailored to specific needs of the user by choosing the appropriate options in the input file. Integration of ICAN with general purpose finite elements structural analysis is shown schematically in figure 1 and will be discussed further in a later section when structural progressive fracture is simulated. Detailed application of ICAN to concrete is described (ref. 3). 


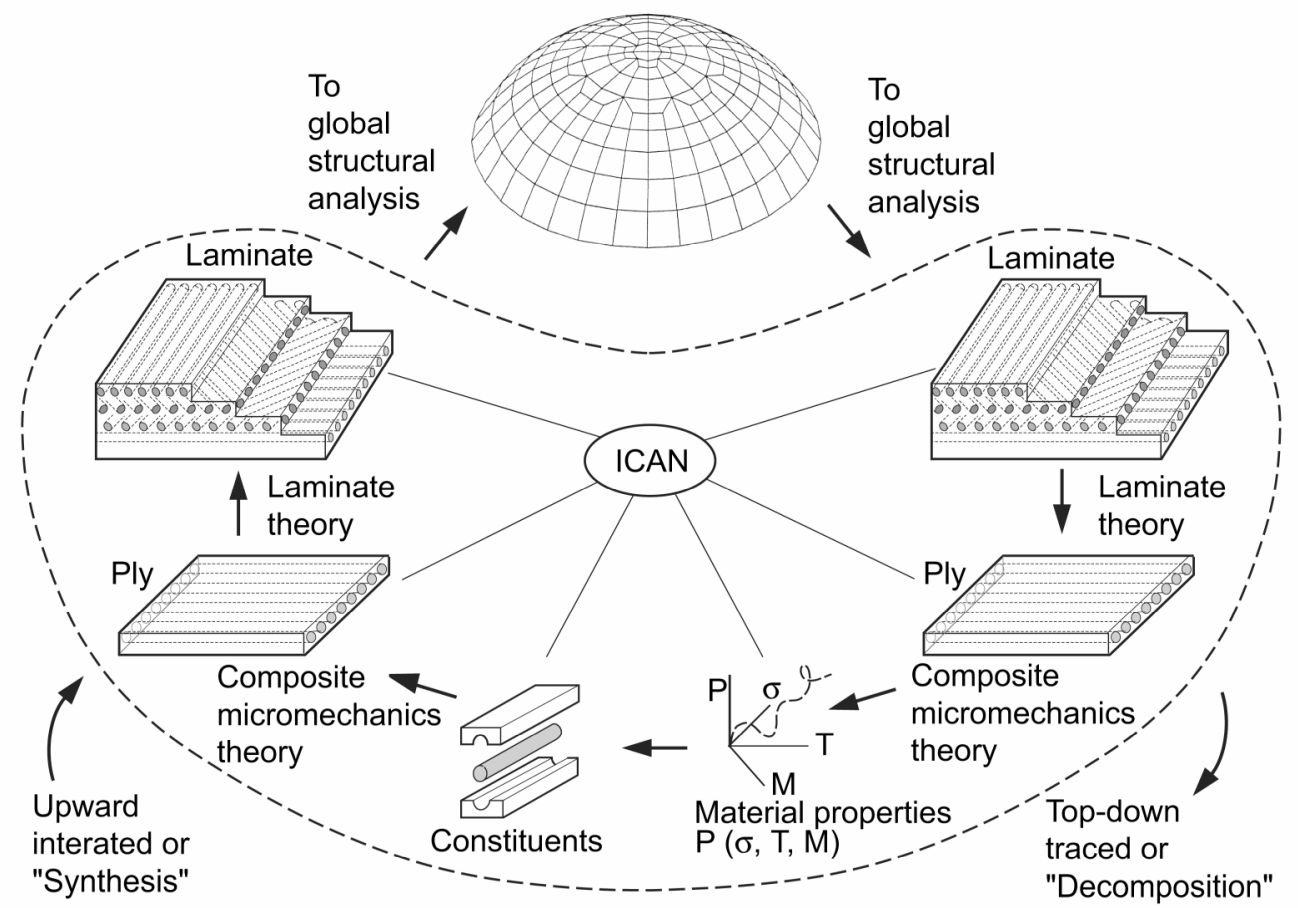

Figure 1.—CODSTRAN simulation cycle.

\section{Composite Enhanced Reinforced Concrete Structural Sections}

The concept is first demonstrated by applying it to a one and two way reinforced concrete section. Then it is applied to a special arch and a dome both made from reinforced concrete.

The section investigated is $h=25.4 \mathrm{~cm}$ (10 in.) deep by $b=15.24 \mathrm{~cm}$ (6 in.) wide. It is one-way reinforced with $1.27 \mathrm{~cm}(0.50 \mathrm{in}$.) diameter steel reinforced bars (fig. 2(a)). The section is represented by plies as shown in figure 2(a). For this application, it was assumed that the section was damaged (cracked at the bottom) and was subsequently repaired by unidirectional composite laminates. The properties assumed for the different materials were: concrete modulus $=20.68 \mathrm{GPa}(3 \mathrm{Mpsi})$, strength $=2.07 \mathrm{MPA}$ (300 psi) tension, 20.7 MPa (3,000 psi) compressions; steel modulus $=206.8 \mathrm{GPa}$ (30 Mpsi), yield strength $137.9 \mathrm{MPa}(20,000 \mathrm{psi})$ tension. The area of the reinforcing steel bars is 4.5 percent of the concrete structural section $(\mathrm{h} \times \mathrm{b}$, fig. 2(a)). The section is enhanced with E-Glass/Epoxy with a 0.55 fiber volume ratio, composite modulus $=38.0 \mathrm{GPa}(5.5 \mathrm{Mpsi})$ and tensile strength $=1.38 \mathrm{MPa}(200 \mathrm{ksi})$. The results obtained for the one-way section are plotted in figure 3 . As can be seen, the enhancement is substantial (two times) for a relatively small composite thickness and increases linearly with composite thickness. Comparable results for the two-way slab (fig. 2(b)) are plotted in figure 4. The enhancements are even greater than for the one-way slab. 


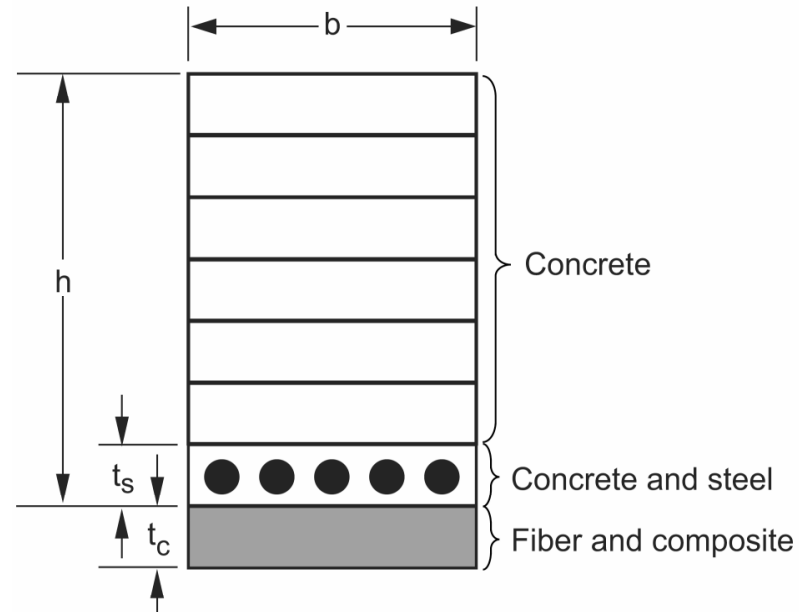

(a)

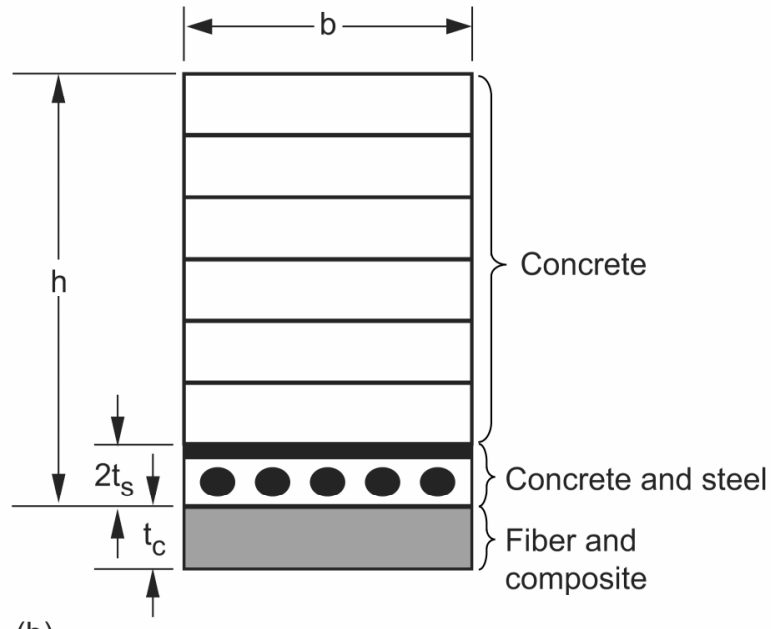

(b)

Figure 2.-Composite repaired/enhanced concrete. Infra structure sections. (a) One-way-reinforced section. (b) Two-way-reinforced section. Notes: percent steel $=\left(A_{S} / h b\right) \times 100$, equivalent fiber volume ratio for steel ply $=A_{S} / t_{S} b$, composite thickness ratio $=t_{C} / h$.

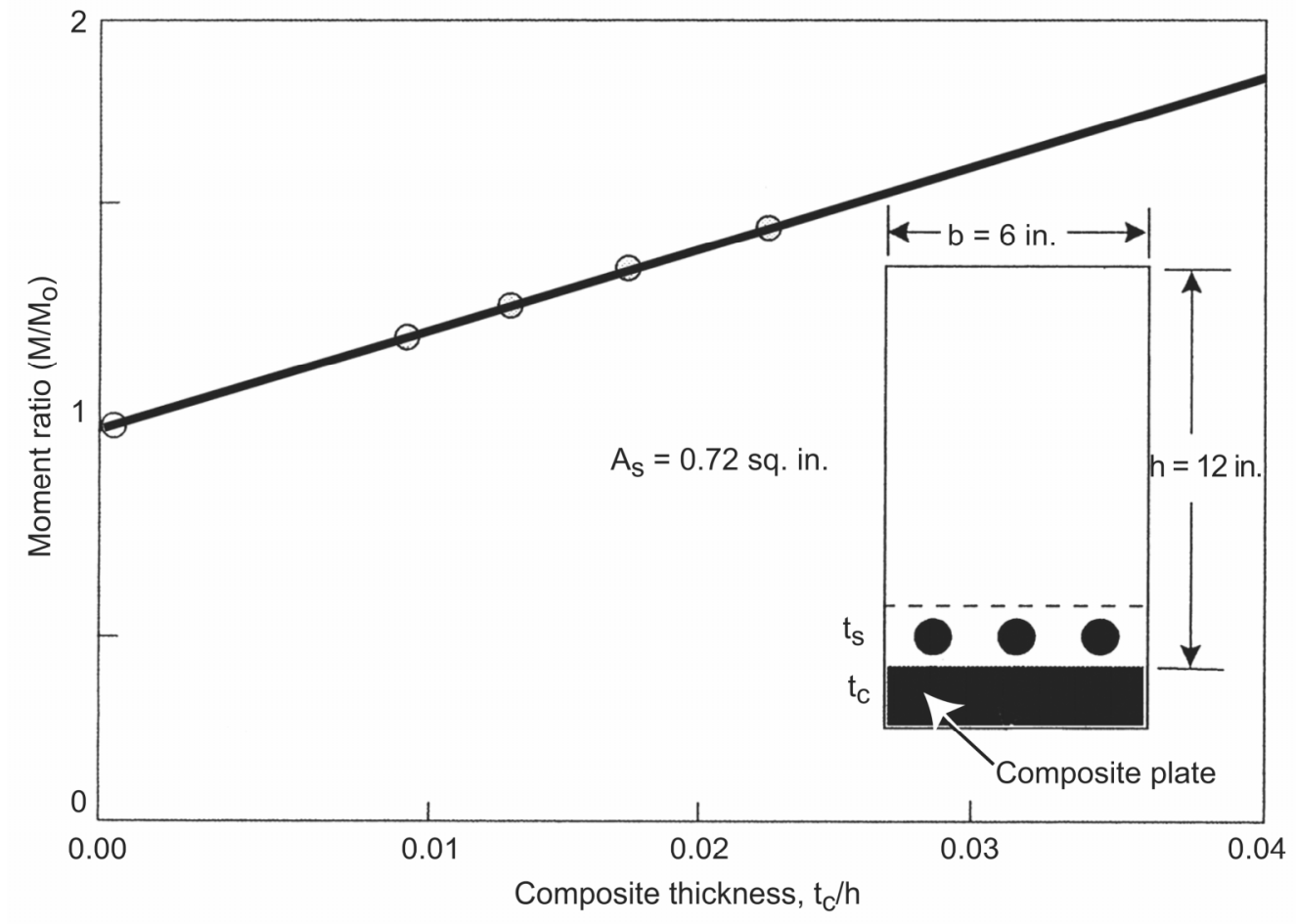

Figure 3.-Beam enhanced design moment by composite, E-G/E; 0.55 FVR. 


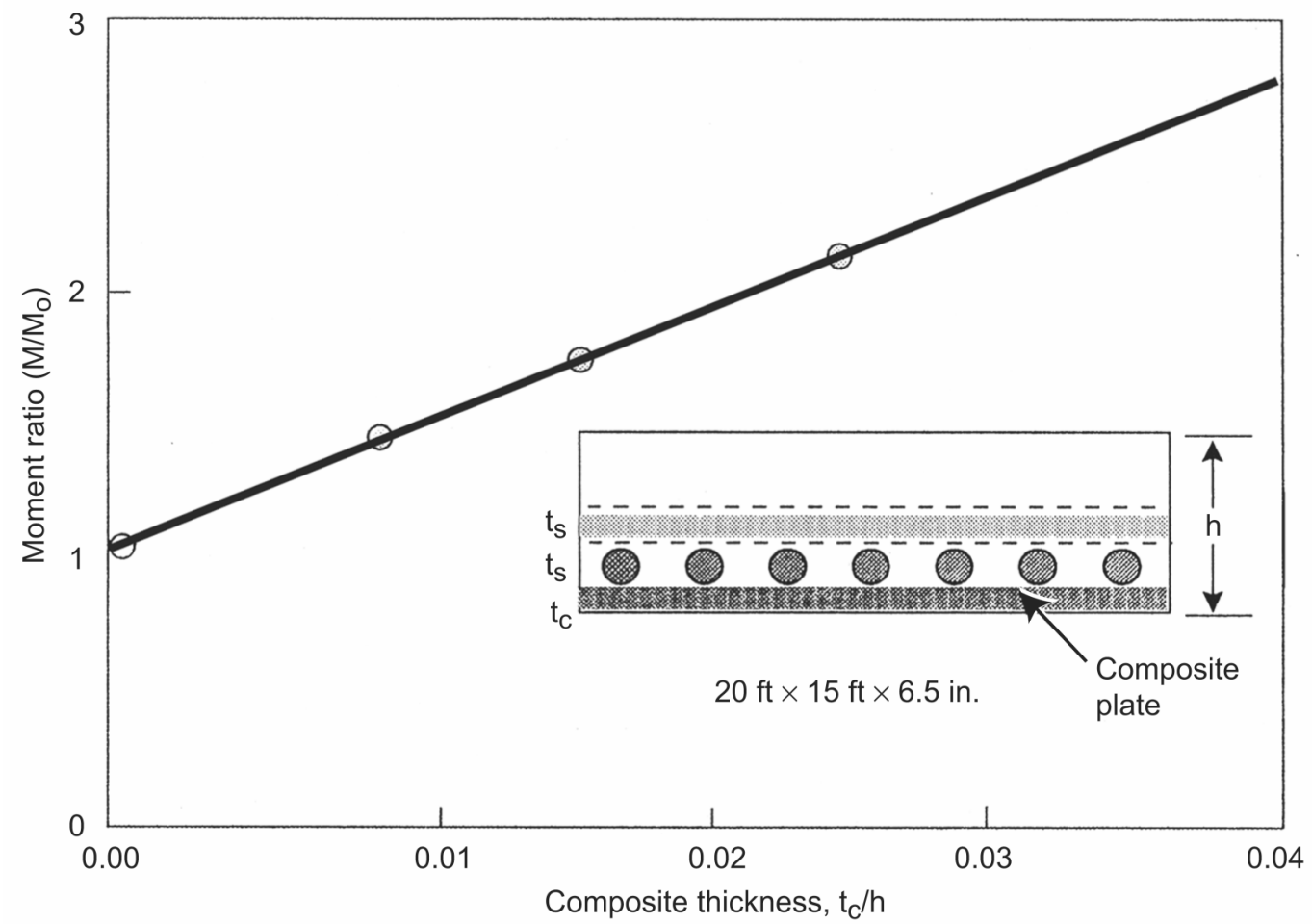

Figure 4.-Slab enhanced design moment by composite, E-G/E; $0.55 \mathrm{FVR}$.

\section{Composite Enhanced Special Reinforced Concrete Arch}

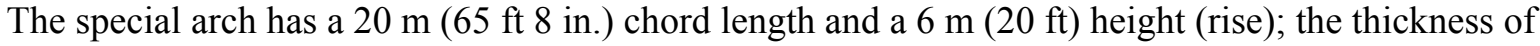
the arch $25.4 \mathrm{~cm}$ (10 in.). The structural section is reinforced with two-way steel at the inner, outer, and mid surfaces. The total volume ratio of the steel in the section is 0.67 percent. The arch is $26.0 \mathrm{~cm}$ (10 ft 3 in.) wide at the base and $32 \mathrm{~cm}(1 \mathrm{ft} 7 \mathrm{in}$.) wide at the crown. A finite element model schematic of the arch and its structural sections are shown in figure 5. The arch is first evaluated without composite enhancement for two different load conditions; concentrated load at the crown and uniform pressure. Subsequently, it is re-evaluated with composite enhancements. The load carrying capacity of the reinforced concrete arch (without the composite enhancement) is determined incrementally by progressive fracture by using CODSTRAN (ref. 6). The concentrated fracture load obtained by using CODSTRAN is $172.4 \mathrm{KN}$ (38.8 Kips) while the collapse pressure is $0.019 \mathrm{MPa}(2.8)$ psi. The CODSTRAN results for progressive fracture are show (fig. 6) for the concentrated load and in figure 7 for the uniform pressure. Two curves are plotted in each figure, one is for the accumulation of progressive damage and the other is for the vertical displacement at the crown. Note both of the curves are normalized by their respective maximum values as noted in those figures. The important observations from the curves in figure 6 are: 1) the crown displacement curve is smooth while 2) the cumulative progressive fracture is very non-smooth. The deviations from non-smooth indicate discontinuities (jumps) in the damaged volume where load magnitudes for damage initiation, slow growth, and rapid propagation to fracture are easily identifiable. Examining the curves in figure 7, it is seen that the vertical displacement is smooth and nonlinear, and the progressive damage accumulation is smoother than that for the concentrated load. However, pressure at which damage initiation, slow and rapid progression to fracture occur, are readily identifiable. 


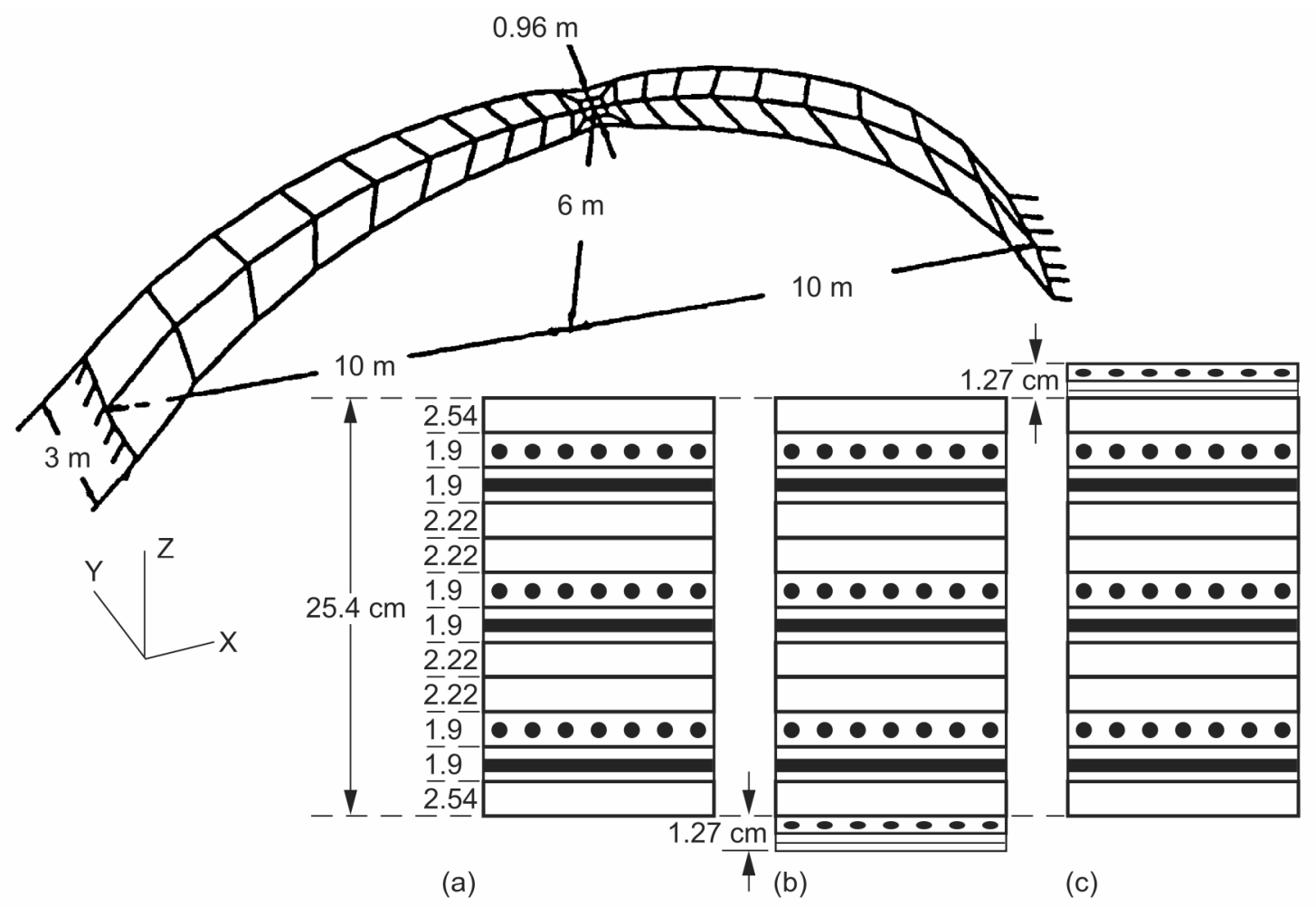

Figure 5.-Arch reinforced concrete structure. Structural section, reinforced concrete arch with composite enhancements. (a) Unenhanced. (b) Enhanced at bottom. (c) Enhanced at top.

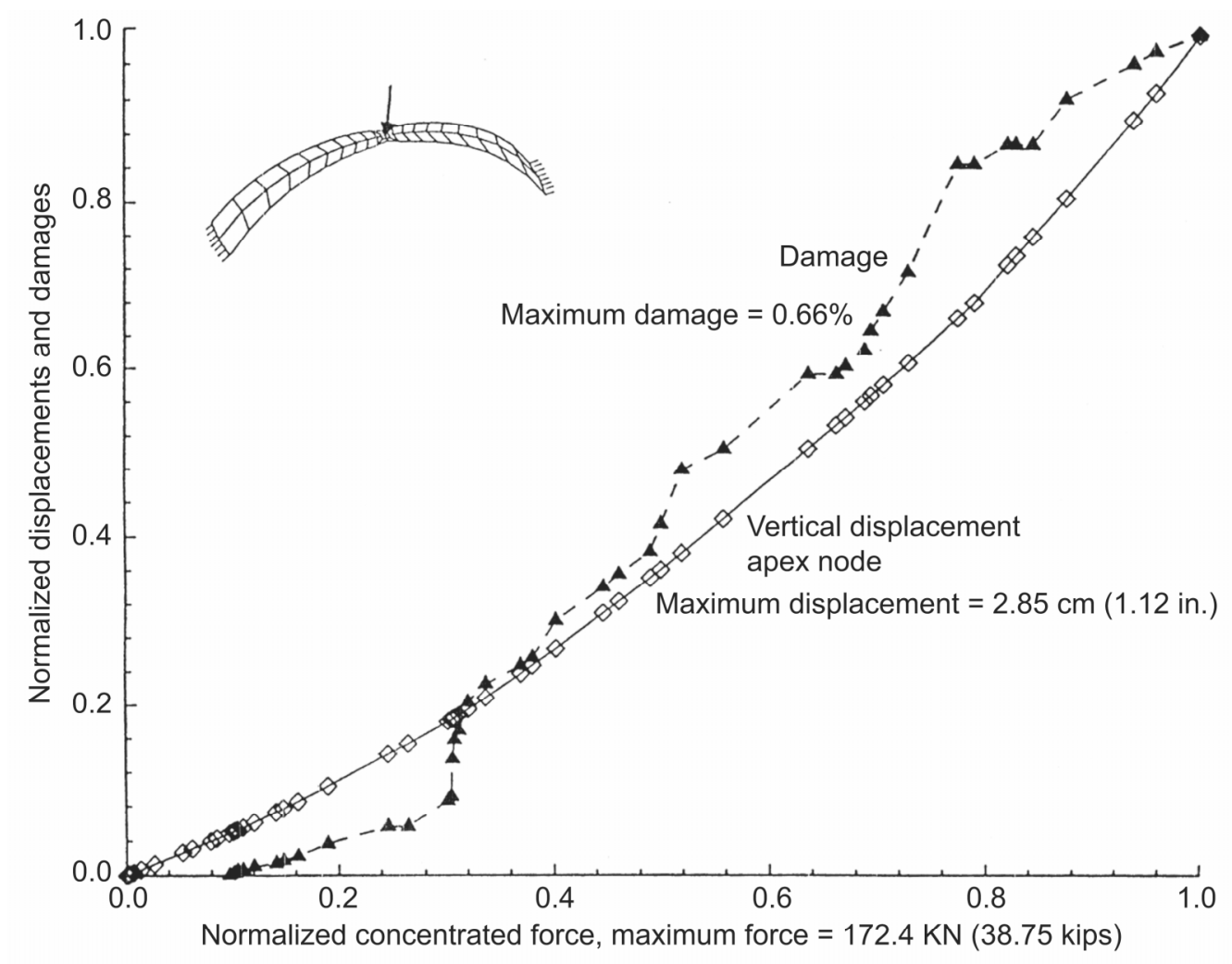

Figure 6.-Effect of the concentrated load on the damage and displacements (arch concrete structure). 


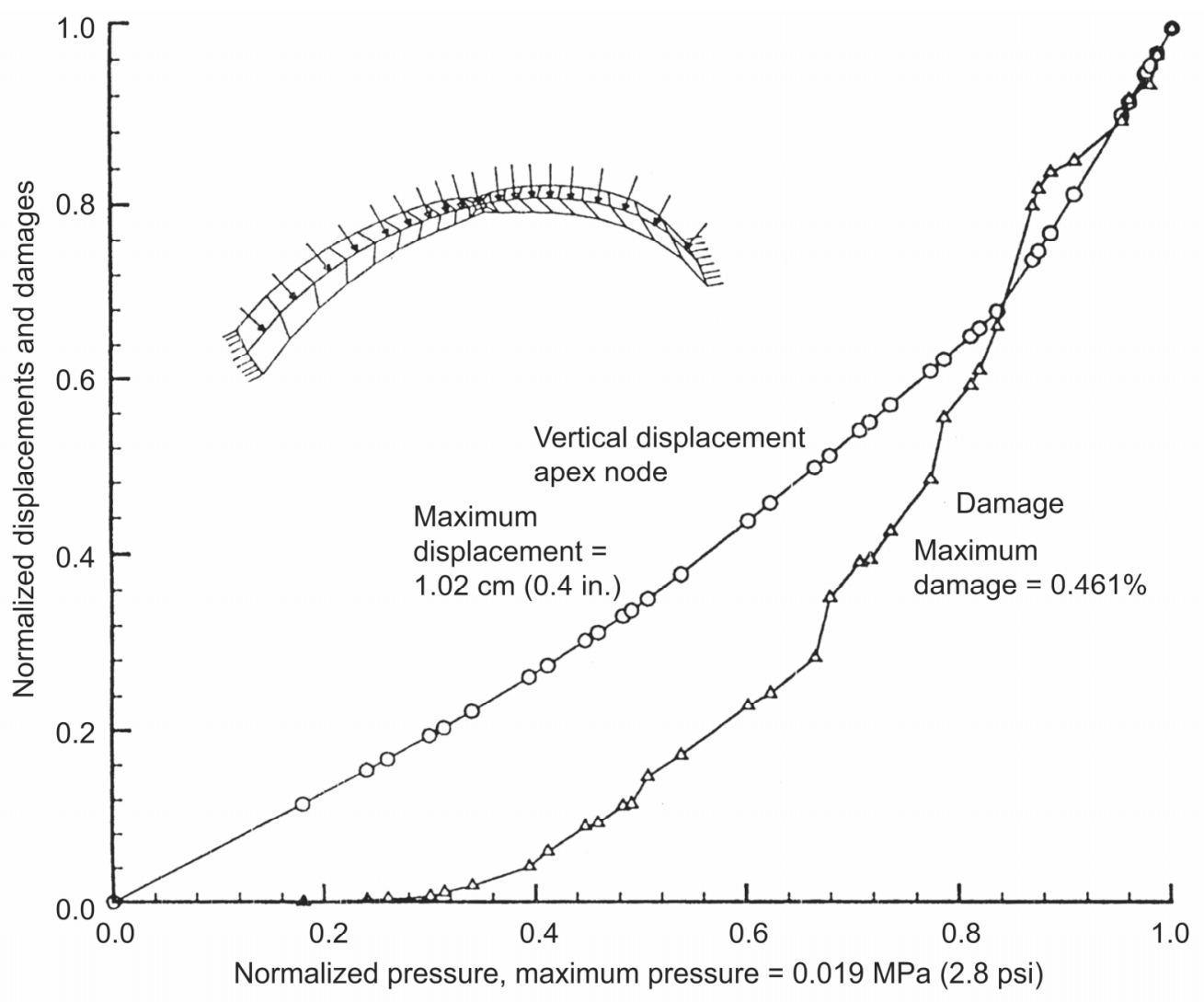

Figure 7.-Effect of the uniform pressure on the damage and displacements.

The degradation of structural performance of the arch with respect to other structural performance variables such as frequencies and buckling loads can be readily evaluated at the end of each load increment when the damaged structure is in equilibrium with the applied external loads. For example, the degradation of the concentrated buckling load of the arch is shown in figure 8, and for its first four vibration frequencies is shown in figure 9. As can be seen in figure, the buckling load starts to degrade with damage initiation (fig. 6) is at about 10 percent of the fracture load and continues to degrade rapidly with damage accumulation. The degradation of the vibration frequencies (fig. 9) is not as rapid as that for the buckling load. The important conclusion from the evaluation of the special arch is that composite mechanics coupled with finite element structural analysis provide unique capability to evaluate the structural performance of reinforced concrete structures. The arch was enhanced by applying composite layers. The composite layers consist of E-glass/epoxy at about 0.55 fiber volume ratio. The layer thickness was $1.27 \mathrm{~cm}(0.50 \mathrm{in}$.). The results for progressive damage and structural fracture are shown in figure 10. Three curves are plotted in this figure. One is the same as that for the un-enhanced arch (fig. 6). The other two are for the composite enhanced load carrying capability of the arch-one on the top surface and one on the bottom surface. As can be seen, the enhancements are substantial when the composite is placed on the bottom surface. 


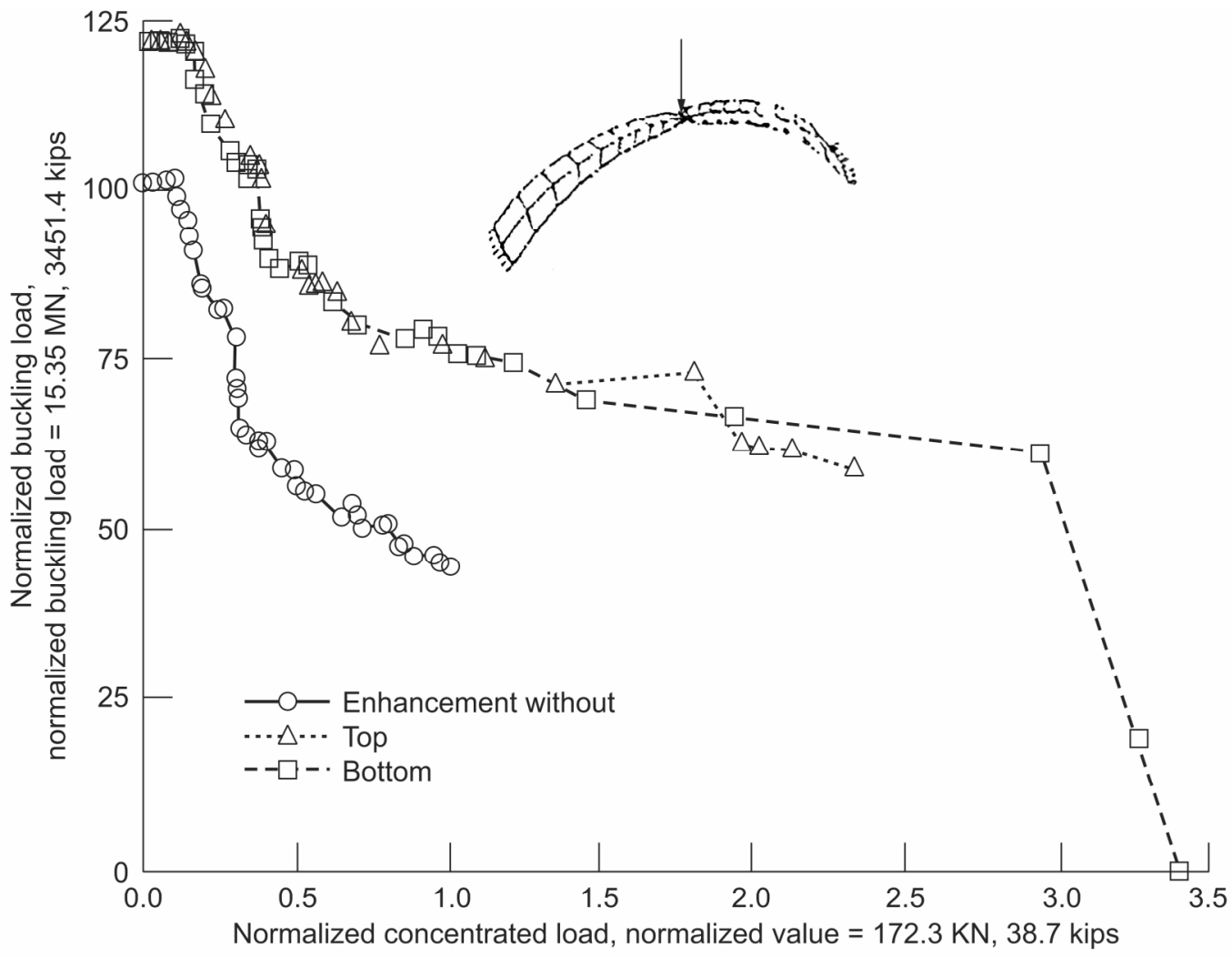

Figure 8.-Specialty concrete reinforced arch: concentrated buckling load degradation.

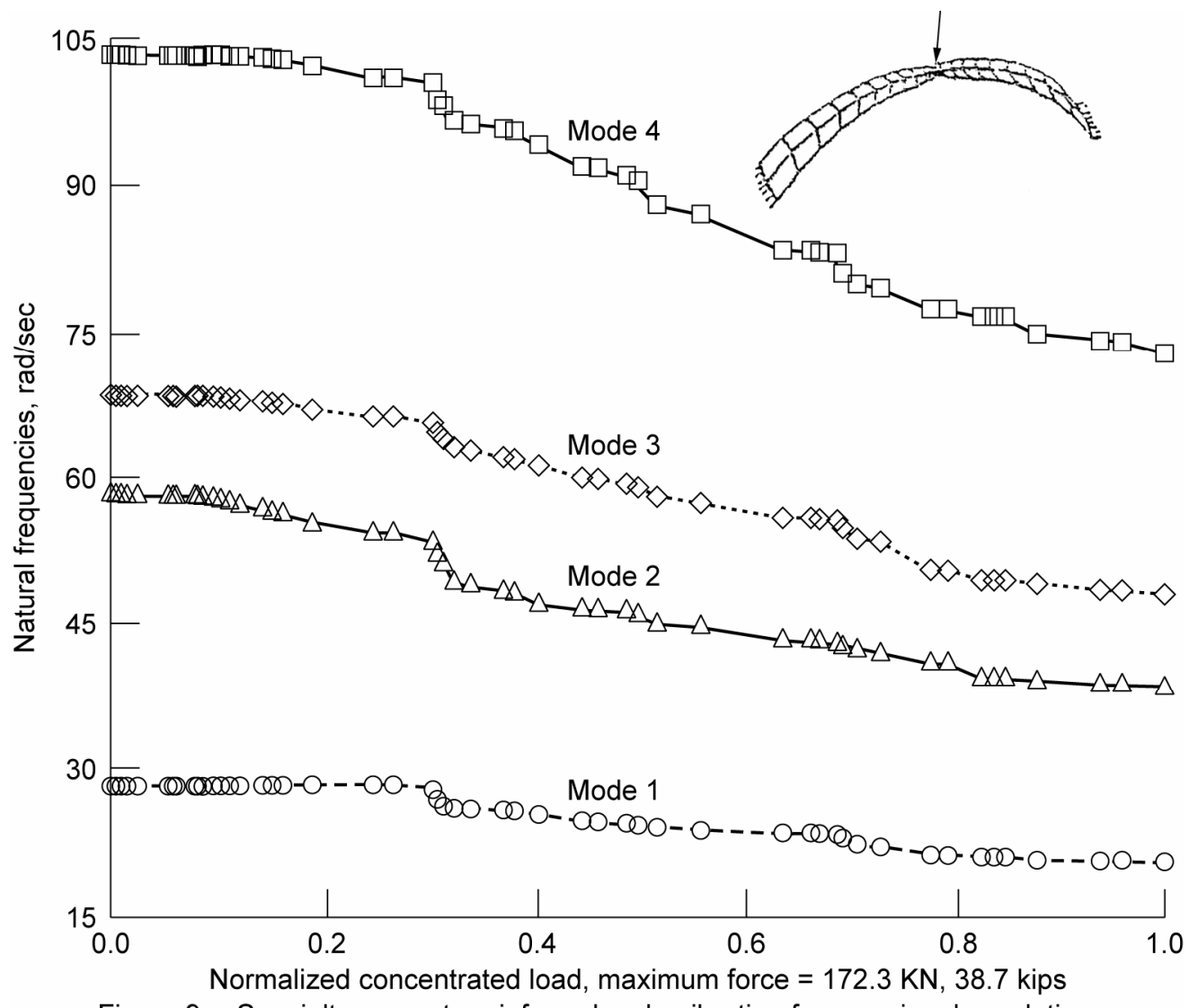

Figure 9.-Specialty concrete reinforced arch: vibration frequencies degradation. 


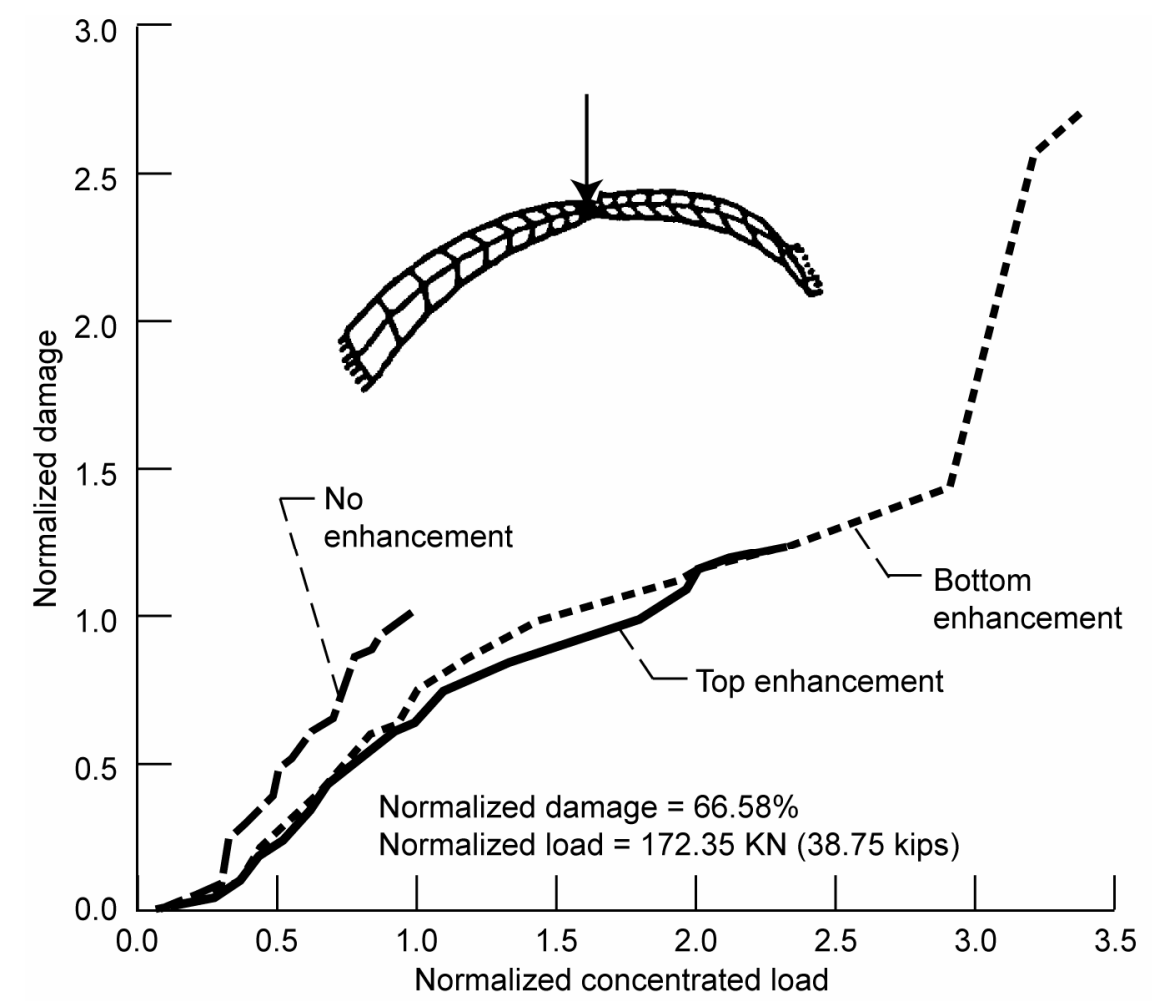

Figure 10.-Progressive structural fracture of a concrete-reinforced arch with and without composite enhancements.

\section{Composite Enhanced Reinforced Concrete Dome}

The concrete dome has $20 \mathrm{~m}(65 \mathrm{ft} 8 \mathrm{in}$.) chord and $6 \mathrm{~m}(20 \mathrm{ft})$ high rise. The structural section is identical to that for the special arch (fig. 5(b)). A finite element model schematic of the dome is shown in figure 11. The dome is first evaluated without the composite enhancement and then with it. The fracture dome is subjected to two different loading conditions; concentrated load at the crown and uniform pressure load. The fracture load for both conditions is determined by cumulative progressive structural fracture by using CODSTRAN (ref. 6). The concentrated fracture load for the dome obtained by using CODSTRAN is $310 \mathrm{KN}$ (69.72 Kips) while that for the uniform pressure is $0.34 \mathrm{MPa}$ (4.91) psi.

Normalized values of the crown vertical displacement and the damage accumulated are plotted versus normalized force in figure 12 for the concentrated load and in figure 13 for the uniform pressure. Examining the two curves in figure 12, it is seen that the vertical displacement is almost linear to about 30 percent from the structural fracture loads damage initiates at about 4 percent of the fracture loads. Both damage progression and vertical displacement increase very rapidly as the fracture load is approached. Note that there is less slow damage growth compared to that of the arch. One conclusion from figure 12 is that the dome exhibits limited damage tolerance when subjected to concentrated load at the crown.

Normalized values of the crown vertical displacement and the accumulated damage are plotted versus normalized pressure in figure 13. The important observation from these curves is that the dome exhibits linear behavior until very close (within 2 percent) to the fracture pressure. Damage initiates sat about 98 percent of the fracture pressure and increases very rapidly for the next 2 percent to fracture. There is a rapid increase in the crown vertical displacement in the remaining last 2 percent of the load. The important conclusion is that the reinforced concrete domes subjected to uniform pressure provide no discriminating information of imminent fracture. 

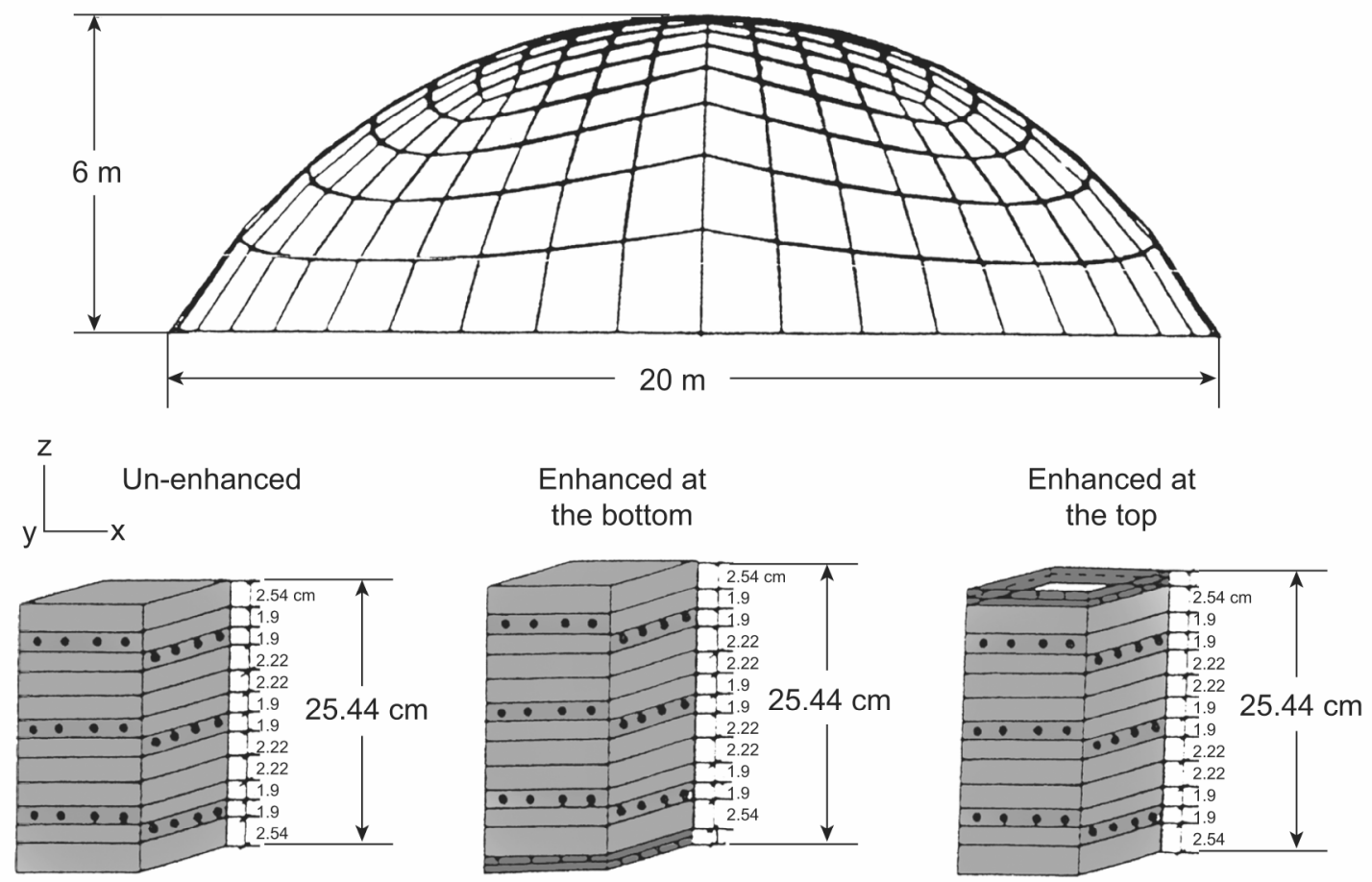

Figure 11.-Reinforced concrete dome geometry and structural sections.

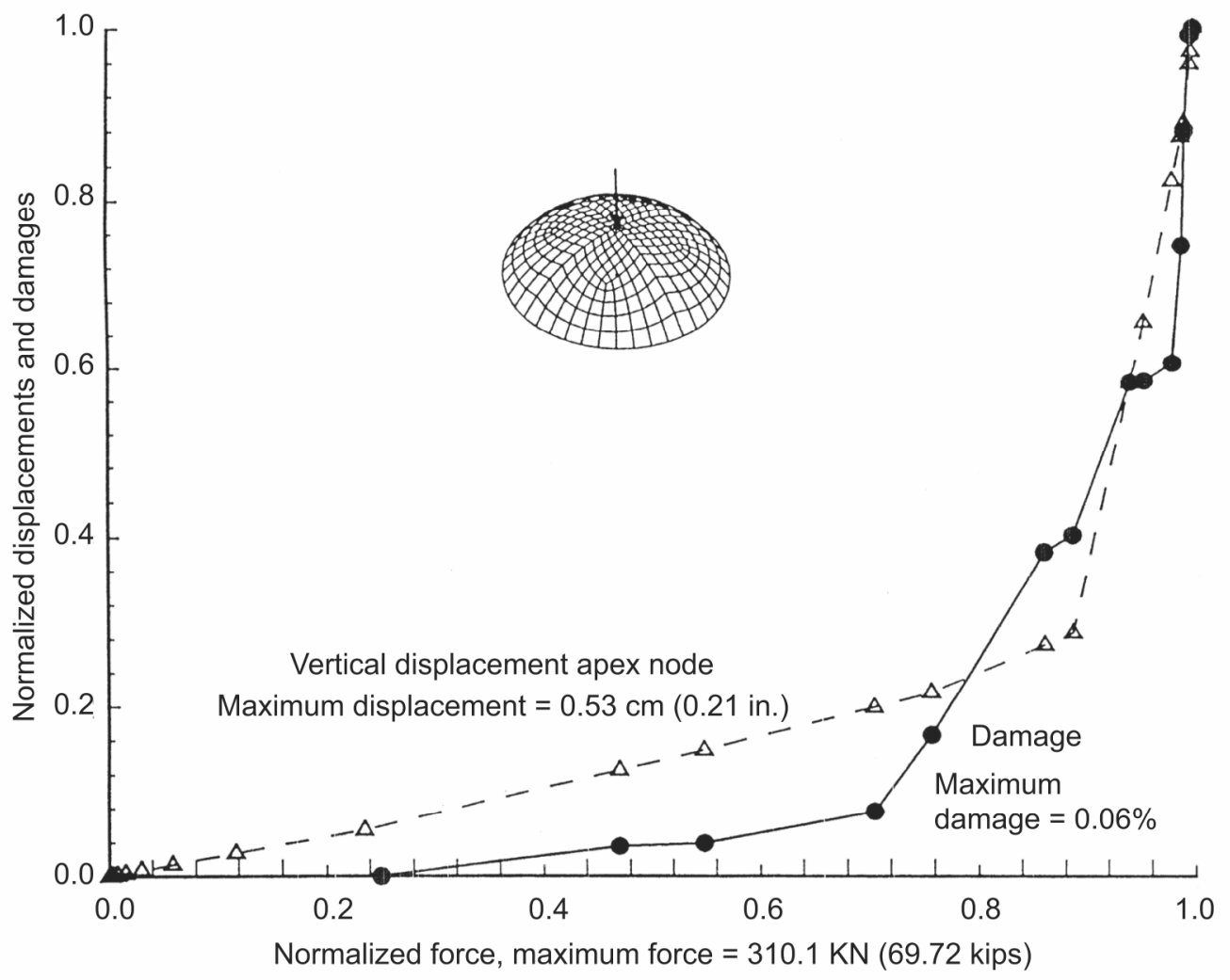

Figure 12.-Effect of the concentrated force on the damage and displacements. 


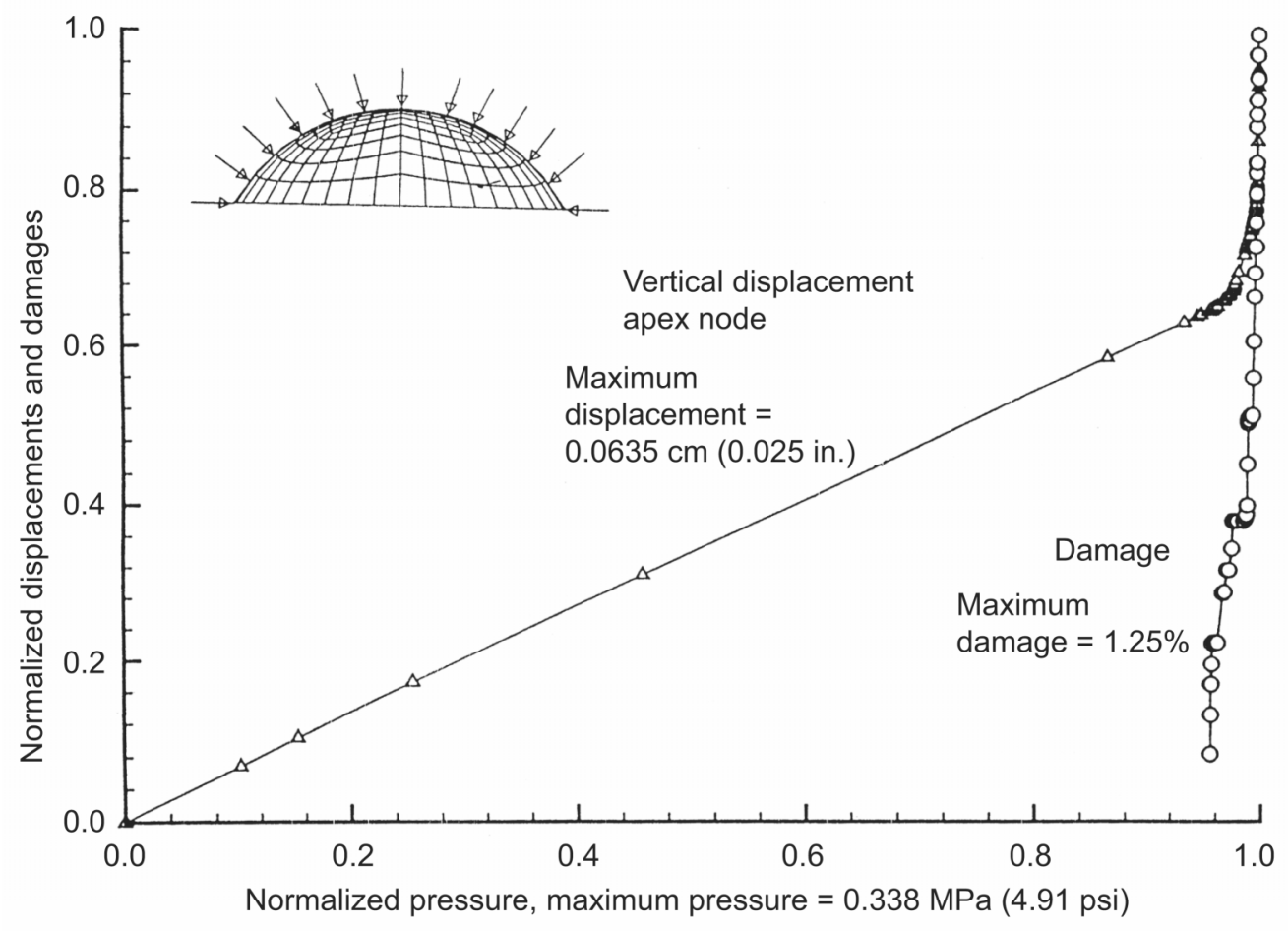

Figure 13.-Dome structure effect of the pressure on the damage and displacements. Pressure load. Dome reinforced concrete structure.

The buckling load of the un-enhanced dome, subjected to concentrated load at the crown, is shown in figure 14 where normalized values are plotted. It is seen that the buckling load is very, very high compared to the fracture load (at least 100 times). It is also seen that buckling load starts degrading at about 23 percent of the fracture load. This latter result is interesting because it indicates that progressive damage must initiate at about this value. Re-examination of the curves in figure 12 reveals that this is consistent with the point at which damage initiates. Note that the buckling load decreases to about 50 percent just prior to fracture. The degradation in the first four vibration modes is shown in figure 15. Insignificant or negligible degradation occurs prior to fracture. Apparently, the frequencies are not as sensitive a measure or degradation as is the buckling load.

The reinforced concrete dome is enhanced with the same composite layers as is the special arch. The enhanced results are shown in figure 16 where the damage is plotted versus load for three different cases: un-enhanced, composite enhanced at the top, and composite enhanced at the bottom. It is very interesting to note that the composite enhancement at the top increases the fracture load by twofold, while that at the bottom only about 20 percent.

The important conclusions are: 1) the load carrying capacity of reinforced concrete structures can be substantially enhanced by the judicious use of fiber composite layers and 2) computational simulation capabilities which are suitable combinations of composite mechanics and general finite element structural analysis appear to be appropriate to evaluate composite enhanced reinforced concrete structures. 


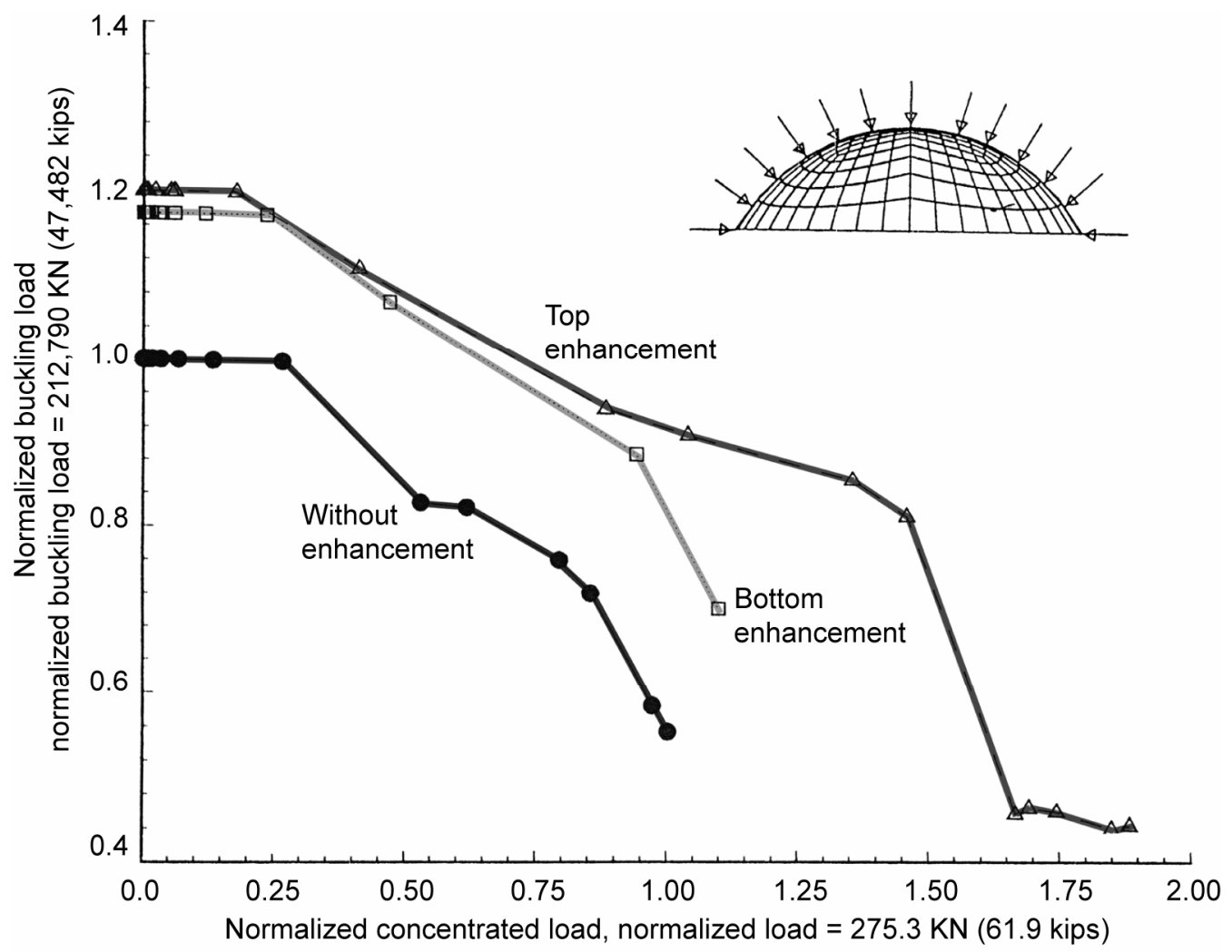

Figure 14.-The effect of the damage on the buckling load. Concentrated load. Dome reinforced concrete structure.

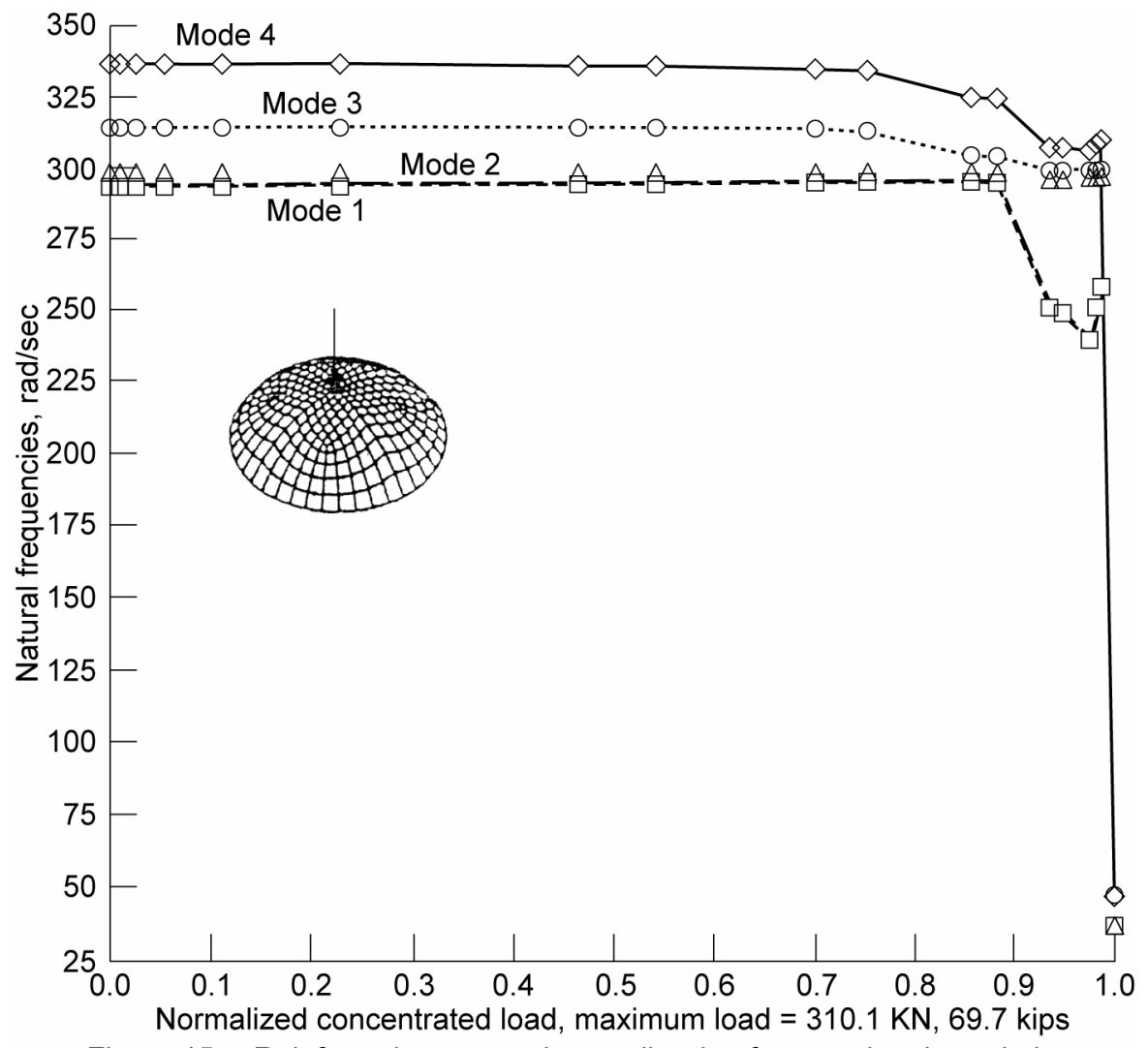

Figure 15.-Reinforced concrete dome: vibration frequencies degradation. 


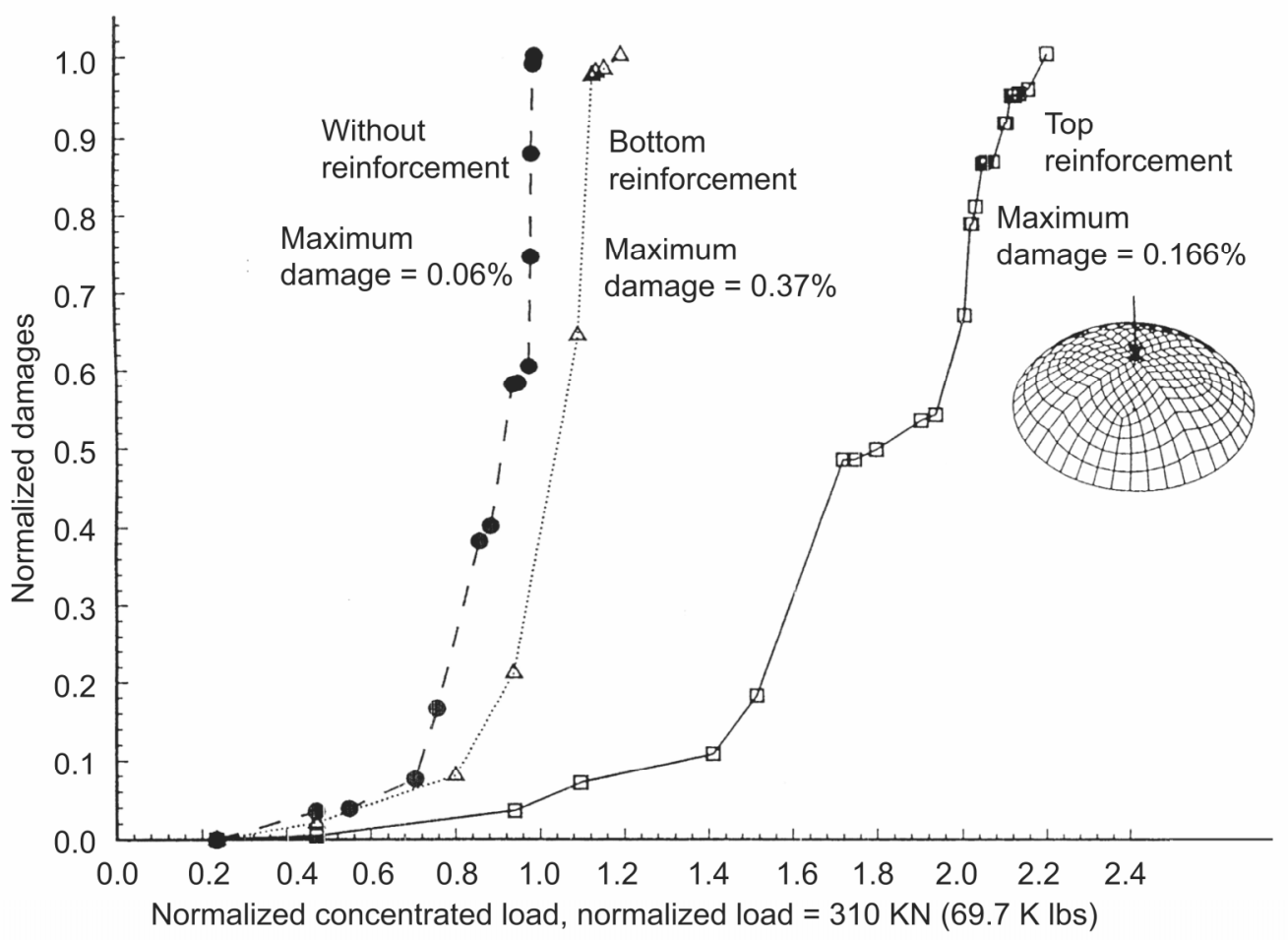

Figure 16.-The effect of the applied load on the damage. Concentrated load. Dome reinforced concrete structure.

\section{General Comments}

The results presented previously constitute a relatively small sample of what can be done by using composite mechanics in conjunction with general purpose finite element structural analysis and composite structural progressive fracture concepts. Obviously, any structural component or assemblies of structural components can be simulated for load carrying capability; fracture loads setting safety factors; designing monitoring devices; scheduling inspection intervals; planning repairs; a composite enhancement that is relatively thin compared to the section and does not introduce asymmetries. Even if it did, composite mechanics and the finite element structural analysis will account for any asymmetry effects on the section performance.

\section{Conclusions}

The important conclusions from an investigation to use composite mechanics for designing composite enhanced structural sections and structures are:

- Composite mechanics can be used to design un-enhanced and enhanced reinforced concrete structural sections.

- Substantial increases in load carrying capacities can be obtained (at least two times) with relatively thin composite layer enhancements.

- Composite mechanics in conjunction with general purpose finite element structural analysis and composite structural progressive fracture can be used to obtain the load carry carrying enhancement of reinforced concrete structures. These load enhancements can be as high as three times that of the un-enhanced. 
- Structural degradation resulting from progressive fracture can be evaluated for losses in buckling loads and vibration frequencies. Buckling loads are more sensitive to damage than vibration frequencies.

- The damage tolerance of reinforced concrete structures and those with composite enhancements can be evaluated from the progressive structural fracture history as the magnitude of damage sustained from damage initiation to damage for imminent structural fracture.

- The combination of composite mechanics with finite element structural analysis and composite progressive fracture is sufficiently general and can be applied to all type of non-enhanced and composite enhanced reinforced concrete structures.

\section{References}

1. Several volumes of Spring Conferences, SAMPE, Covina, CA.

2. Mital, S.K., Gotsis, P.K. and Chamis, C.C., "Laminate Analogy for Composites Application to Infrastructures." Invited paper for the Conference Proceedings of International SAMPE Symposium 42, May 3-5, 1997, Anaheim, CA.

3. Mital, S.K. and Chamis, C.C., "Thermal and Mechanical Behavior of Particulate Composite Materials, Materials and Design Technology, ASME. PD. 62.275, (1994).

4. Murthy, P.L.N., Ginty, C.A. and Santfeliz, J.G., "Second Generation Integrated Composite Analyzer (ICAN) Computer Code.” NASA TP-3200, (1993).

5. Caruso, J.J. and Chamis, C.C., Journal of Composite Technology \& Research, Vol. 8(3) 77, (1986).

6. Chamix, C.C., Murthy, P.L.N. and Minnetyan, L., "Progressive Fracture of Polymer Matrix Composite Structures." Elsevier Science B.V., reprinted from Theoretical and Applied Fracture Mechanics. 25, 1 (1996). 
Public reporting burden for this collection of information is estimated to average 1 hour per response, including the time for reviewing instructions, searching existing data sources, gathering and maintaining the data needed, and completing and reviewing the collection of information. Send comments regarding this burden estimate or any other aspect of this collection of information, including suggestions for reducing this burden, to Washington Headquarters Services, Directorate for Information Operations and Reports, 1215 Jefferson Davis Highway, Suite 1204, Arlington, VA 22202-4302, and to the Office of Management and Budget, Paperwork Reduction Project (0704-0188), Washington, DC 20503.

\begin{tabular}{|l|l|l|}
\hline 1. AGENCY USE ONLY (Leave blank) & $\begin{array}{c}\text { 2. REPORT DATE } \\
\text { January } 2006\end{array}$ & $\begin{array}{r}\text { 3. REPORT TYPE AND DATES COVERED } \\
\text { Technical Memorandum }\end{array}$ \\
\hline
\end{tabular}

\section{TITLE AND SUBTITLE}

Application of Composite Mechanics to Composites Enhanced Concrete Structures

\section{AUTHOR(S)}

Christos C. Chamis and Pascal K. Gotsis

\section{FUNDING NUMBERS}

WBS 561581.02.08.03

8. PERFORMING ORGANIZATION REPORT NUMBER

E-15395

National Aeronautics and Space Administration

John H. Glenn Research Center at Lewis Field

Cleveland, Ohio 44135-3191

10. SPONSORING/MONITORING AGENCY REPORT NUMBER

National Aeronautics and Space Administration

Washington, DC 20546-0001

NASA TM-2006-214038

\section{SUPPLEMENTARY NOTES}

Prepared for the 16th European Conference of Fracture cosponsored by ESIS, ASTM, SMS, AIAS, JSEM, BSSM, SEM, and EURASEM, Alexandroupolis, Greece, July 3-7, 2006. Christos C. Chamis, e-mail: Christos.C.Chamis@nasa.gov, NASA Glenn Research Center; and Pascal K. Gotsis, e-mail: pkgotsis@email.teiser.gr, Technical Education Institute, Terma Magnisias Str, TK62124, Serres, Greece. Responsible person, Christos C. Chamis, organization code $\mathrm{R}, 216-433-3252$.

\begin{tabular}{l|l} 
12a. DISTRIBUTION/AVAILABILITY STATEMENT & 12b. DISTRIBUTION CODE
\end{tabular}

Unclassified - Unlimited

Subject Category: 39

Available electronically at http://gltrs.grc.nasa.gov

This publication is available from the NASA Center for AeroSpace Information, 301-621-0390.

13. ABSTRACT (Maximum 200 words)

A new and effective method is described to design composites to repair damage or enhance the overload strength of concrete infrastructures. The method is based on composite mechanics which is available in computer codes. It is used to simulate structural sections made from reinforced concrete which are typical in infrastructure as well as select reinforced concrete structures. The structural sections are represented by a number of layers through the thickness where different layers are used in concrete, and for the composite. The reinforced concrete structures are represented with finite elements where the element stiffness parameters are from the structural sections which are represented by composite mechanics. The load carrying capability of the structure is determined by progressive structural fractural. Results show up to 40 percent improvements for damage and for overload enhancement with relatively small laminate thickness for the structural sections and up to three times for the composite enhanced select structures (arches and domes).

\section{SUBJECT TERMS} 15. NUMBER OF PAGES

Displacement; Energy; Finite elements; Stresses 20

\begin{tabular}{|c|c|c|}
\hline $\begin{array}{c}\text { 17. SECURITY CLASSIFICATION } \\
\text { OF REPORT } \\
\text { Unclassified }\end{array}$ & $\begin{array}{c}\text { 18. SECURITY CLASSIFICATION } \\
\text { OF THIS PAGE } \\
\text { Unclassified }\end{array}$ & $\begin{array}{c}\text { 19. SECURITY CLASSIFICATION } \\
\text { OF ABSTRACT } \\
\text { Unclassified }\end{array}$ \\
\hline
\end{tabular}



